\title{
Kribbella solani sp. nov. and Kribbella jejuensis sp. nov., isolated from potato tuber and soil in Jeju, Korea
}

Correspondence

Joo-Won Suh

jwsuh@mju.ac.kr

\author{
Jaekyeong Song, ${ }^{1,3}$ Byung-Yong Kim, ${ }^{1}$ Seung-Beom Hong, ${ }^{1}$ \\ Hyun-Suk Cho, ${ }^{1}$ Kyounghee Sohn, ${ }^{2}$ Jongsik Chun ${ }^{2}$ and Joo-Won Suh ${ }^{3}$ \\ ${ }^{1} \mathrm{KACC}$, Genetic Resources Division, National Institute of Agricultural Biotechnology, Suwon, \\ 441-707, Korea \\ ${ }^{2}$ School of Biological Sciences, Seoul National University, Seoul, 151-742, Korea \\ ${ }^{3}$ Department of Biological Science, Myong Ji University, Yongin 449-728, Korea
}

The genus Kribbella established by Park et al. (1999) contains LL-diaminopimelic acid (LL-DAP) in its cell wall peptidoglycan and lies within the family Nocardioidaceae (Nesterenko et al., 1985, 1990). Two species, Kribbella flavida and Kribbella sandramycini, included in this genus were originally assigned to the genus Nocardioides ('Nocardioides fulvus' IFO 14399 and Nocardioides sp. ATCC 39419 , respectively) based on $16 \mathrm{~S}$ rDNA sequence analysis. Recently, Hongia koreensis (Lee et al., 2000) was transferred to this genus as Kribbella koreensis on the basis of its molecular systematics (Sohn et al., 2003). Here, we present polyphasic characterization of two novel Kribbella strains isolated during a taxonomic survey of the potato scab caused by Streptomyces spp. from Jeju, Korea (Song et al., 2004).

Published online ahead of print on 30 April 2004 as DOI 10.1099/ ijs.0.02953-0.

\footnotetext{
Abbreviation: LL-DAP, LL-diaminopimelic acid.

The GenBank/EMBL/DDBJ accession numbers for the 16S rDNA sequences of strains KACC $20196^{\top}$, KACC 20248', KACC $20249^{\top}$, KACC 20250 ${ }^{\top}$ and KACC 20266 ${ }^{\top}$ are AY253862-AY253866, respectively.

An extended neighbour-joining tree and a maximum-parsimony tree for the isolates and related actinomycete taxa are available as supplementary data in IJSEM Online.
}

Strain DSA1 ${ }^{\mathrm{T}}$ was isolated from a potato tuber with scab lesions. For isolation, the tuber was washed twice with distilled water and scraped lesions were suspended in distilled water using a vortex mixer. The suspension was plated on GYM agar (DSMZ medium no. 65; http://www. dsmz.de/media/media.htm) using the dilution method and cultured at $30{ }^{\circ} \mathrm{C}$ for 5 days. Strain $\mathrm{HD}^{\mathrm{T}}$ was isolated from soil of a potato-cultivating field using the same growth conditions and the dilution plating method.

Growth and morphological properties of the isolates were recorded from GYM agar, ISP media (Shirling \& Gottlieb, 1966) and trypticase soy agar (TSA; BBL 11768). Melanin formation was examined on ISP media 6 and 7 . For scanning electron microscopy, cells grown at $30^{\circ} \mathrm{C}$ for 5 days on GYM agar were prepared by cutting agar blocks fixed with $1 \%$ osmium tetroxide and observed under a scanning electron microscope (Hitachi S-2460N). Both strains grew on GYM agar, TSA, nutrient agar and all ISP media at $28^{\circ} \mathrm{C}$. The two strains did not produce melanin pigment. Their colonies were sand-pasty and had lichenous shapes with irregular edges on GYM agar. Aerial mycelium of the isolates was white and consisted of hyphae that fragmented into rodshaped elements.

Physiological characteristics were examined using standard 
procedures (Lee et al., 2000; Williams et al., 1983) at $30^{\circ} \mathrm{C}$ for up to 5 days. In addition, catalase activity, nitrate reduction, urease activity, hydrogen sulfide production and hydrolysis of arbutin, casein, aesculin, gelatin and starch were tested as described by MacFaddin (2000). Antimicrobial activity was examined against Bacillus subtilis, Pseudomonas aeruginosa, Micrococcus luteus, Streptomyces scabiei, Candida albicans, Aspergillus niger, Trichoderma harzianum, Fusarium acuminatum and Colletotrichum gloeosporioides. Physiological characteristics are given in the species descriptions and in Table 1 .

Genomic DNA extraction, PCR amplification of 16S rDNA and cloning were done as described previously (Song et al., 2004). 16S rDNA sequences were analysed using an Applied Biosystems DNA sequencer (ABI3100) and aligned using CLUSTAL W software (Thompson et al., 1994). Nucleotide similarity values were calculated from the alignment. An evolutionary distance matrix was constructed using the algorithm of Jukes \& Cantor (1969) and phylogenetic trees for the datasets were inferred from the neighbour-joining method of Saitou \& Nei (1987) using MEGA version 2.1 (Kumar et al., 2001). The stability of relationships was evaluated by

Table 1. Differential physiological characteristics of isolates $\mathrm{DSA} 1^{\top}$ and $\mathrm{HD9}^{\top}$ and type strains of Kribbella species

Strains: 1, DSA1 ${ }^{\mathrm{T}}$; 2, $\mathrm{HD9}^{\mathrm{T}}$; 3, K. flavida KACC $20248^{\mathrm{T}}$ (data from Park et al., 1999 unless indicated); 4, K. sandramycini KACC $20249^{\mathrm{T}}$ (Park et al., 1999); 5, K. koreensis KACC $20250^{\mathrm{T}}$ (Lee et al., 2000). +, Positive; -, negative; $\mathrm{W}$, weakly positive; ND, not done.

\begin{tabular}{|c|c|c|c|c|c|}
\hline Characteristic & 1 & 2 & 3 & 4 & 5 \\
\hline \multicolumn{6}{|c|}{ Use of sole carbon sources: } \\
\hline D-Xylose & + & + & - & + & + \\
\hline D-Arabinose & + & + & - & $\mathrm{W}$ & + \\
\hline D-Mannose & + & - & - & + & + \\
\hline L-Rhamnose & + & + & - & + & + \\
\hline$\alpha$-Lactose & + & + & - & + & + \\
\hline Galactose & - & + & - & + & + \\
\hline Adonitol & - & - & + & + & + \\
\hline Xylitol & - & - & - & + & - \\
\hline myo-Inositol & - & - & + & + & ND \\
\hline Mannitol & - & - & + & + & + \\
\hline Salicin & + & - & $\mathrm{ND}$ & $\mathrm{ND}$ & + \\
\hline Inulin & - & + & + & + & + \\
\hline \multicolumn{6}{|l|}{ Hydrolysis of: } \\
\hline Tween $80^{*}$ & + & - & + & + & - \\
\hline Elastin & - & - & + & + & + \\
\hline Urea & - & + & + & + & + \\
\hline Starch & - & - & - & $\mathrm{W}$ & + \\
\hline Casein & - & $\mathrm{W}$ & + & + & + \\
\hline \multicolumn{6}{|l|}{ Growth at: } \\
\hline $15^{\circ} \mathrm{C}^{\star}$ & - & - & - & - & + \\
\hline $37^{\circ} \mathrm{C}$ & - & + & + & + & + \\
\hline
\end{tabular}

${ }^{\star}$ Data determined in this study. performing bootstrap analysis of the neighbour-joining data based on 1000 resamplings.

Phylogenetic analysis based on 16S rDNA sequences indicated that our isolates belong to the genus Kribbella with $100 \%$ bootstrap support (Fig. 1). Strain $\mathrm{DSAl}^{\mathrm{T}}$ showed the highest similarity to K. sandramycini KACC $20249^{\mathrm{T}}$ $(98 \cdot 6 \%)$, followed by K. flavida KACC $20248^{\mathrm{T}}(98 \cdot 5 \%)$, strain HD9 $^{\mathrm{T}}(98 \cdot 2 \%)$ and $K$. koreensis KACC $20250^{\mathrm{T}}$ $(98 \cdot 1 \%)$. Strain $\mathrm{HD}^{\mathrm{T}}$ showed the closest similarity to strain $\operatorname{DSAl}^{\mathrm{T}}(98 \cdot 2 \%)$, followed by $K$. sandramycini KACC $20249^{\mathrm{T}}(98 \%)$, K. flavida KACC $20248^{\mathrm{T}}(97 \cdot 9 \%)$ and K. koreensis KACC $20250^{\mathrm{T}}(97 \cdot 7 \%)$. An extended neighbour-joining tree and a maximum-parsimony tree using PAUP version 4.0b10 (Swofford, 2000) are available as supplementary data in IJSEM Online.

DNA-DNA relatedness between the isolates and type strains of the Kribbella species were determined using the slot-blot hybridization method of Chun et al. (1998). Our isolates showed relatively low DNA-DNA relatedness of $42 \cdot 5 \%$. Isolate $\mathrm{DSAl}^{\mathrm{T}}$ showed a low level of DNA-DNA relatedness with $K$. sandramycini $(0 \%), K$. koreensis $(16 \cdot 4 \%)$ and K. flavida $(50 \cdot 4 \%)$. Similarly, isolate $\mathrm{HD}^{\mathrm{T}}$ showed a low level of DNA-DNA relatedness with $K$. sandramycini $(0 \%)$, K. koreensis $(20 \cdot 9 \%)$ and K. flavida $(47 \cdot 8 \%)$.

Biomass for most of the chemotaxonomic studies was prepared following growth of the isolates and standard strains in shake flasks of GYM for 5 days at $30^{\circ} \mathrm{C}$; after a check for purity, biomass was harvested by centrifugation, washed twice in distilled water and freeze-dried. Integrated lipid and wall analysis were carried out by previously described methods: wall amino acids (O'Donnell et al., 1985), diaminopimelic acids (Staneck \& Roberts, 1974), sugars (Saddler et al., 1991), menaquinone (O’Donnell et al., 1985) and polar lipids (Minnikin et al., 1984). Whole-cell fatty acid profile was determined on TSA (BBL 11768) using the MIDI (Microbial Identification) system. Both strains had LL-DAP, alanine, glycine and glutamic acid in the cell wall peptidoglycan, contained mannose, glucose, galactose and ribose as whole cell sugars and MK-9 $\left(\mathrm{H}_{4}\right)$ as the major menaquinone, as for other Kribbella species. Polar lipid profiles of

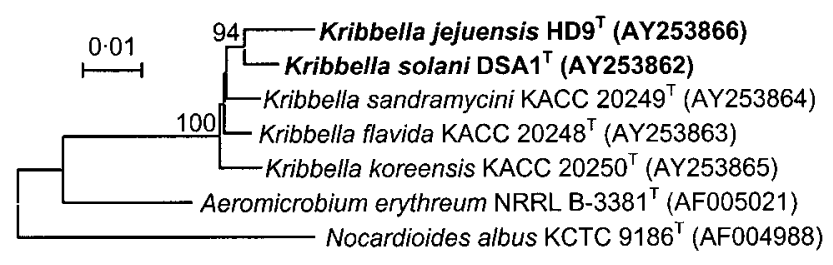

Fig. 1. Phylogenetic tree showing the relationship of isolates $\mathrm{DSA}^{\top}$ and $\mathrm{HD9}^{\top}$ and related actinomycete taxa. Numbers at branching points indicate percentages of occurrence based on neighbour-joining analyses of 1000 resampled dataset bootstrapped trees. Bar, one nucleotide substitution per 100 nucleotides. 
the two strains revealed diphosphatidylglycerol, phosphatidylcholine and phosphatidylinositol. Whole-cell fatty acid profiles of our isolates and other Kribbella species are given in Table 2. The $\mathrm{G}+\mathrm{C}$ content of the DNA was determined using the thermal denaturation method of Marmur \& Doty (1962): values were $69 \cdot 2$ and $68 \pm 1 \mathrm{~mol} \%$, for strains $\mathrm{DSA}^{\mathrm{T}}$ and $\mathrm{HD} 9^{\mathrm{T}}$, respectively.

From genotypic and phenotypic characterization, it is evident that our isolates not only belong to the genus Kribbella but also represent novel species. Along with molecular data, a number of phenotypic characters can be used to differentiate the isolates from recognized Kribbella species and

Table 2. Cellular fatty acid profiles of isolates $D S A 1^{\top}$ and $\mathrm{HD9}^{\top}$ and type strains of Kribbella species on TSA medium

Strains: 1 , DSA1 ${ }^{\mathrm{T}}$; 2, HD9 ${ }^{\mathrm{T}}$; 3, K. flavida KACC $20248^{\mathrm{T}}$; 4, K. sandramycini KACC $20249^{\mathrm{T}}$; 5, K. koreensis KACC $20250^{\mathrm{T}}$. Values of less than $1 \%$ are not shown. TBSA, Tuberculostearic acid.

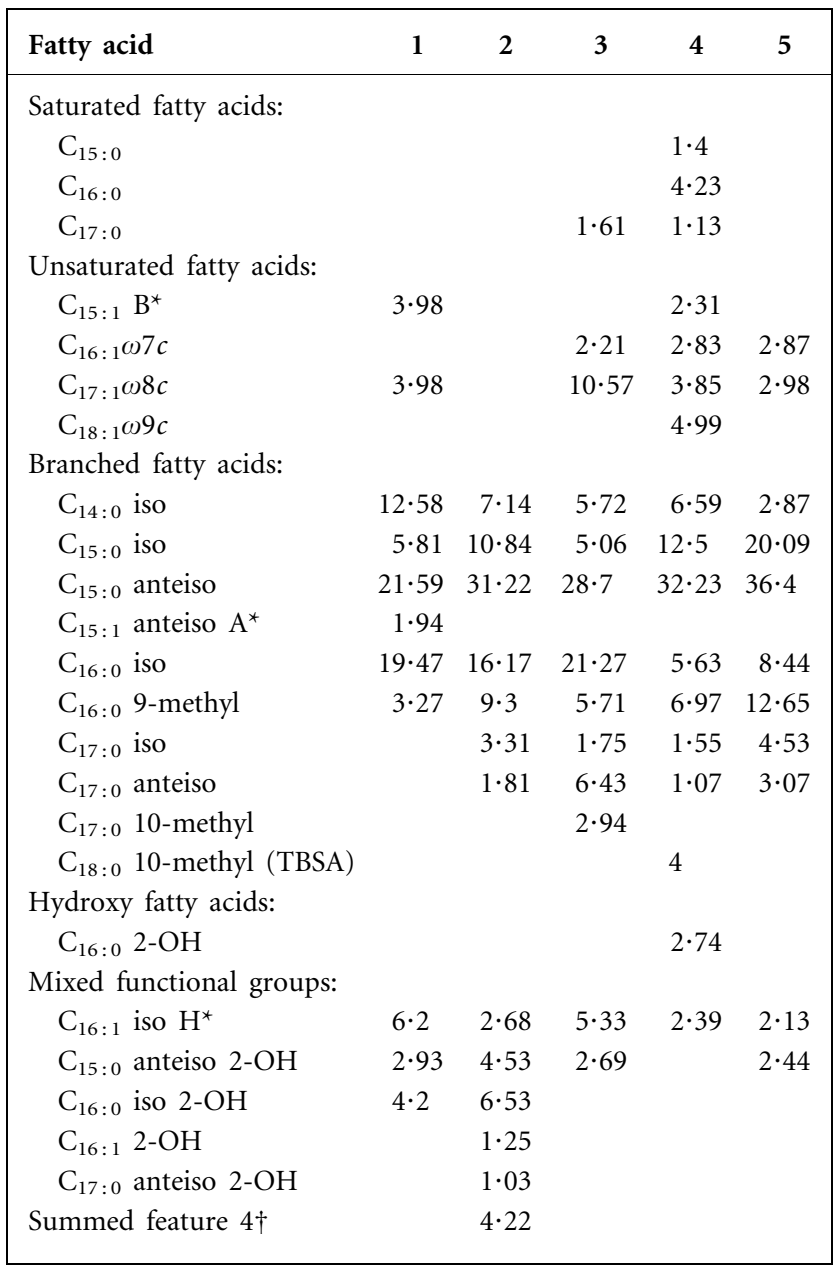

*The double bond position indicated by a capital letter is unknown. $\dagger$ Summed features represent groups of two or three fatty acids that could not be separated by GLC with the MIDI system. Summed feature 4 contained one or more of $\mathrm{C}_{15: 0}$ iso $2-\mathrm{OH} / \mathrm{C}_{16: 1} \omega 9 t$. from each other (Tables 1 and 2). We therefore propose two novel species, Kribbella solani sp. nov. for strain DSA1 ${ }^{\mathrm{T}}$ and Kribbella jejuensis sp. nov. for strain $\mathrm{HD}^{\mathrm{T}}$.

\section{Description of Kribbella solani sp. nov.}

Kribbella solani (so.la' ni. N.L. gen. n. solani of Solanum, the genus of the potato, Solanum tuberosum, from which the type strain was isolated).

Aerial mycelium is white and consists of hyphae that fragment into rod-shaped elements. Vegetative mycelium is creamy and shows hyphae that are broadly branched. Colonies are sand-pasty and have lichenous shapes with irregular edges. No diffusible pigment is formed. Non-motile. Nitrate is not reduced to nitrite. Catalase-positive. Ureasenegative. Utilizes glucose, sucrose, D-xylose, D-arabinose, D-melezitose, D-mannose, L-rhamnose, $\alpha$-lactose, trehalose, melibiose, cellobiose, raffinose and salicin as carbon sources. Utilizes L-histidine, DL-arginine, DL- $\alpha$-amino- $n$-butyric acid, trans-4-hydroxy-L-proline and potassium nitrate as nitrogen sources. Grows at $28-30^{\circ} \mathrm{C}$ but not at 15 or $37^{\circ} \mathrm{C}$. Grows at $\mathrm{pH} 7$ but not at $\mathrm{pH} 4$ or 10. DNA, Tween 80 , aesculin, arbutin and tributyrin are hydrolysed. Xanthine, hypoxanthine, xylan, elastin, adenine, guanine, tyrosine, allantoin, casein, chitin and starch are not hydrolysed. Tolerant to $0.01 \%$ lysozyme, $2 \% \mathrm{NaCl}, 0.1 \%$ phenyl ethanol and $0.001 \%$ potassium tellurite but not to $0.01 \%$ sodium azide, $0.01 \%$ thallous acetate and $0.1 \%$ phenol. Resistant to $4 \mu \mathrm{g}$ tetracycline, $10 \mu \mathrm{g}$ gentamicin, $80 \mu \mathrm{g}$ neomycin, $4 \mu \mathrm{g}$ rifamficin, $20 \mu \mathrm{g}$ streptomycin, $4 \mu \mathrm{g}$ vancomycin and $4 \mu \mathrm{g}$ tobramycin $\mathrm{ml}^{-1}$, but susceptible to $10 \mu \mathrm{g}$ treoleandomycin $\mathrm{ml}^{-1}$. Weakly resistant to $10 \mathrm{U}$ penicillin $\mathrm{G} \mathrm{ml}^{-1}$. Antimicrobial activity is not observed. Cell wall peptidoglycan contains LL-DAP, alanine, glycine and glutamic acid. Mannose, glucose, galactose and ribose are present as whole cell sugars. The predominant fatty acids are 12-methyltridecanoic acid, 12-methyltetradecanoic acid and 14-methylpentadecanoic acid. The genomic DNA G $+\mathrm{C}$ content is about $69 \mathrm{~mol} \%$.

The type strain, DSA1 ${ }^{\mathrm{T}}\left(=\mathrm{KACC} 20196^{\mathrm{T}}=\mathrm{JCM} 12205^{\mathrm{T}}\right)$, was isolated from a potato tuber with scab lesions from Jeju, Korea. The species description is based on the type strain only.

\section{Description of Kribbella jejuensis sp. nov.}

Kribbella jejuensis (je.ju.en'sis. N.L. fem. adj. jejuensis referring to Jeju, Korea).

Aerial mycelium is white and consists of hyphae that fragment into rod-shaped elements. Vegetative mycelium is creamy and shows hyphae that are broadly branched. Colonies are sand-pasty and have lichenous shapes with irregular edges. No diffusible pigment is formed. Non-motile. Nitrate is not reduced to nitrite. Catalase- and ureasepositive. Utilizes glucose, sucrose, D-xylose, D-arabinose, D-melezitose, galactose, L-rhamnose, $\alpha$-lactose, trehalose, melibiose, cellobiose, raffinose and inulin as carbon 
sources. Utilizes L-histidine, DL-arginine, DL-homoserine, DL- $\alpha$-amino- $n$-butyric acid, trans-4-hydroxy-L-proline and potassium nitrate as nitrogen sources. Grows at $28-37^{\circ} \mathrm{C}$ but not at 15 or $45^{\circ} \mathrm{C}$. Grows at $\mathrm{pH} 7$ but not at $\mathrm{pH} 4$ or 10. Gelatin, aesculin, arbutin and tributyrin are hydrolysed. Tween 80, xanthine, hypoxanthine, xylan, elastin, adenine, guanine, tyrosine, allantoin, casein, chitin and starch are not hydrolysed. Tolerant to $0.01 \%$ lysozyme, $1 \% \mathrm{NaCl}$, $0.1 \%$ phenyl ethanol and $0.001 \%$ potassium tellurite but not to $0.01 \%$ sodium azide, $0.01 \%$ thallous acetate or $0.1 \%$ phenol. Resistant to $1 \mu \mathrm{g}$ tetracycline, $0.4 \mu \mathrm{g}$ gentamicin, $4 \mu \mathrm{g}$ rifamficin, $1 \mu \mathrm{g}$ streptomycin, $4 \mu \mathrm{g}$ vancomycin and $1 \mu \mathrm{g}$ tobramycin $\mathrm{ml}^{-1}$, but susceptible to $4 \mu \mathrm{g}$ neomycin, $20 \mu \mathrm{g}$ streptomycin and $10 \mu \mathrm{g}$ treoleandomycin $\mathrm{ml}^{-1}$. Weakly resistant to $4 \mu \mathrm{g}$ tobramycin, $4 \mu \mathrm{g}$ streptomycin and $10 \mathrm{U}$ penicillin $\mathrm{G} \mathrm{ml}^{-1}$. Weak antimicrobial activity is observed towards Streptomyces scabiei. Cell wall peptidoglycan contains LL-DAP, alanine, glycine and glutamic acid. Mannose, glucose, galactose and ribose are present as cell wall sugars. The predominant fatty acids are 13-methyltetradecanoic acid, 12-methyltetradecanoic acid and 14-methylpentadecanoic acid. The genomic DNA $\mathrm{G}+\mathrm{C}$ content is about $68 \mathrm{~mol} \%$.

The type strain, HD9 ${ }^{\mathrm{T}}\left(=\mathrm{KACC} 20266^{\mathrm{T}}=\mathrm{JCM} 12204^{\mathrm{T}}\right.$ ), was isolated from soil from Jeju, Korea. The species description is based on the type strain only.

\section{Acknowledgements}

We would like to thank Dr J. P. Euzéby for his valuable help in assigning the specific names to novel isolates.

\section{References}

Chun, J., Seong, C.-N., Bae, K. S., Lee, K.-J., Kang, S.-O., Goodfellow, M. \& Hah, Y. C. (1998). Nocardia flavorosea sp. nov. Int J Syst Bacteriol 48, 901-905.

Jukes, T. H. \& Cantor, C. R. (1969). Evolution of protein molecules. In Mammalian Protein Metabolism, vol. 3, pp. 21-132. Edited by H. N. Munro. New York: Academic Press.

Kumar, S., Tamura, K., Jakobsen, I. B. \& Nei, M. (2001). MEGA2: molecular evolutionary genetics analysis software. Bioinformatics $\mathbf{1 7}$, 1244-1245.

Lee, S. D., Kang, S.-O. \& Hah, Y. C. (2000). Hongia gen. nov., a new genus of the order Actinomycetales. Int J Syst Evol Microbiol 50, 191-199.

MacFaddin, J. F. (2000). Biochemical Tests for Identification of Medical Bacteria, 3rd edn. Edited by L. McGrew. Baltimore: Lippincott Williams \& Wilkins.
Marmur, J. \& Doty, P. (1962). Determination of the base composition of deoxyribonucleic acid from its thermal denaturation temperature. J Mol Biol 5, 109-118.

Minnikin, D. E., O’Donnell, A. G., Goodfellow, M., Alderson, G., Athalye, M., Schaal, A. \& Parlett, J. H. (1984). An integrated procedure for the extraction of bacterial isoprenoid quinones and polar lipids. J Microbiol Methods 2, 233-241.

Nesterenko, O. A., Kvasnikov, E. I. \& Nogina, T. M. (1985). Nocardioidaceae fam. nov., a new family of the order Actinomycetales Buchanan 1917. Microbiol Zh 47, 3-12.

Nesterenko, O. A., Kvasnikov, E. I. \& Nogina, T. M. (1990). Nocardioidaceae fam. nov. In Validation of the Publication of New Names and New Combinations Previously Effectively Published Outside the IJSB, List no. 34. Int J Syst Bacteriol 40, 320-321.

O'Donnell, A. G., Minnikin, D. E. \& Goodfellow, M. (1985). Integrated lipid and wall analysis of actinomycetes. In Chemical Methods in Bacterial Systematics, pp. 131-143. Edited by M. Goodfellow \& D. E. Minnikin. London: Academic Press.

Park, Y.-H., Yoon, J.-H., Shin, Y. K., Suzuki, K., Kudo, Y., Seino, A., Kim, H.-J., Lee, J.-S. \& Lee, S. T. (1999). Classification of 'Nocardioides fulvus' IFO 14399 and Nocardioides sp. ATCC 39419 in Kribbella gen. nov, as Kribbella flavida sp. nov. and Kribbella sandramycini sp. nov. Int J Syst Bacteriol 49, 743-752.

Saddler, G. S., Tavecchia, P., Lociure, S., Zand, M., Colombo, L. \& Selva, E. (1991). Analysis of madurose and other actinomycete whole cell sugars by gas chromatography. J Microbiol Methods 14, 185-191.

Saitou, N. \& Nei, M. (1987). The neighbor-joining method: a new method for reconstructing phylogenetic trees. Mol Biol Evol 4 406-425.

Shirling, E. B. \& Gottlieb, D. (1966). Methods for characterization of Streptomyces species. Int J Syst Bacteriol 16, 313-340.

Sohn, K., Hong, S. G., Bae, K. S. \& Chun, J. (2003). Transfer of Hongia koreensis Lee et al. 2000 to the genus Kribbella Park et al. 1999 as Kribbella koreensis comb. nov. Int J Syst Evol Microbiol 53, 1005-1007.

Song, J., Lee, S.-C., Kang, J.-W., Baek, H.-J. \& Suh, J.-W. (2004). Phylogenetic analysis of Streptomyces spp. isolated from potato scab lesions in Korea on the basis of 16S rRNA gene and 16S-23S rDNA internally transcribed spacer sequences. Int J Syst Evol Microbiol 54, 203-209.

Staneck, J. L. \& Roberts, G. D. (1974). Simplified approach to identification of aerobic actinomycetes by thin-layer chromatography. Appl Microbiol 28, 226-231.

Swofford, D. L. (2000). PAUP ${ }^{*}$. Phylogenetic Analysis Using Parsimony (* and Other Methods), version 4. Sunderland, MA: Sinauer Associates Inc.

Thompson, J. D., Higgins, D. G. \& Gibson, T. J. (1994). CLUSTAL W: improving the sensitivity of progressive multiple sequence alignment through sequence weighting, position-specific gap penalties and weight matrix choice. Nucleic Acids Res 22, 4673-4680.

Williams, S. T., Goodfellow, M., Alderson, G., Wellington, E. M. H., Sneath, P. H. A. \& Sackin, M. J. (1983). Numerical classification of Streptomyces and related genera. J Gen Microbiol 129, 1743-1813. 